\title{
Urena lobata: A green source of anti-oxidant
}

\author{
Dixa Singh*, V. S. Singh \\ Department of Chemistry, H. N. B. Garhwal University Campus- Pauri (Uttarakhand), India
}

Email address:

dixa1974singh@gmail.com (D. Singh)

\section{To cite this article:}

Dixa Singh, V. S. Singh. Urena lobata: A Green Source of Anti-Oxidant. Journal of Plant Sciences. Vol. 2, No. 6, 2014, pp. $299-303$. doi: $10.11648 /$ j.jps.20140206.16

\begin{abstract}
Anti- oxidants are crucial to human health. They have capacity to neutralize the free radicals responsible for giving birth to a variety of diseases. A diet rich in foods with high levels of anti-oxidants is associated with longevity and good health. We tried to replace the chemical anti-oxidants by herbal anti-oxidants. In plants, the anti-oxidants are present as flavonoids,so the flavonoids in Urena lobata were isolated, identified, quantitatively estimated and tested for their anti-oxidant activity.The flavonoids were extracted from the stem and the leaves separately to know the relative contents. Quercetin and Kaempferol were found to exist in the plant material.These were qualitatively tested by the method of Thin Layer Chromatography (TLC). The isolation, purification and quantitative content determination was performed by preparative thin layer chromatography (PTLC). The anti-oxidant activity of the methanolic plant extract was examined by DPPH radical scavenging activity method. The anti-oxidant ability of the plant extract was found comparable with Vitamin C.
\end{abstract}

Keywords: Urena Lobata, Quercetin, Kaempferol, Myrecetin, Silica Gel-G, Ascorbic Acid and DPPH

\section{Introduction}

Oxygen is primarily essential to sustain life, but when our bodies use oxygen certain reactive by-products known as free radicals or reactive oxygen species (ROS) are generated. The ROS can attack and damage body cells. Sometimes, the injury to cells may be so serious that cell DNA is damaged and mutated which causes a variety diseases [1].

An Anti-oxidant is a compound which has ability to trap the free radicals. Alkylated phenols are well known antioxidants. The butylated phenol and butylated hydroxyl toluene are the major anti-oxidants used in food industry [24].The synthetic anti -oxidants, though useful, may produce side effects and harm our bodies. The naturally occurring anti-oxidants may provide an answer to this problem. The anti- oxidants present in fruits, vegetables, whole grains, nuts and legumes are already being used to counter ROS [5]. Most of the anti-oxidant compounds in a typical diet are derived from plant sources and belong to various classes of compounds with a wide variety of physical and chemical properties.

Understanding the significance of anti-oxidants, we have tried to isolate these from a plant called Urena lobata. This would provide a green source of anti-oxidants instead the synthetic one. The anti-oxidants are present in plants as flavonoids, so we have isolated, characterized and tested anti- oxidant activity of the flavonoids in the plant.

Urena lobata is a shrub 0.6 to $3.0 \mathrm{~m}$ in height and up to 7 $\mathrm{cm}$ in basal diameter.The species usually has a single stem emerging from the ground but many branches throughout. Axillary flowers are usually solitary and have five pink petals. The fruits are 8 to $10 \mathrm{~mm}$ globose capsules that break into five fine barbed mericarps. It grows throughout moist tropical and sub- tropical regions. Various extracts of leaves and roots are used in herbal medicines to treat diverse ailments as colic malaria, gonorrhea, fever, wounds, toothache \& rheumatism [6]. The leaves and flowers are eaten as famine food in Africa [7]. Raw leaves are reported to contain $81.8 \%$ moisture, $3.2 \mathrm{~g}$ protein, $0.1 \mathrm{~g}$ fat, $12.8 \mathrm{~g}$ carbohydrates, $1.8 \mathrm{~g}$ fiber, $2.1 \mathrm{~g}$ ash, $0.558 \mathrm{~g}$ calcium and $0.067 \mathrm{~g}$ of phosphorous per $100 \mathrm{~g}$ [8].

\section{Materials and Methods}

\subsection{Plant Material}

The leaves \& stems were collected from Kotdwar region of Garhwal Himalayas in Uttarakhand and authenticated by Prof. A. K. Agarwal, Head, Department of Botany, Govt .P. G.College, Uttarkashi. The stem and leaves were made two separate samples. Each sample was washed in tap water to 
remove dust and adhering impurities and then dried in air under shade. The dried samples were crushed to fine powder and weighed.

\subsection{Chemicals and Instrument}

1,1- diphenyl -2- picryl hydrazyl (DPPH), Quercetin, Myrecetin, Kaempferol were obtained from Sigma chemical, USA, Ascorbic acid from S . D. Fine Chem, India and used as such. Methanol, Ethylacetate , Ether, Petroleum ether, Aluminium chloride, Sodium nitrite, Sodium hydroxide were all $\mathrm{BDH}$ chemicals and used without further purification. The absorbance of a solution was measured on Perking Elmer model 621, spectrophotometer.

\subsection{Extraction of Flavonoids}

A $2 \mathrm{Kg}$ sample each of leaves and stem was extracted separately with 10 liter of $80 \%$ methanol for 6 days and filtered. The crude methanolic solution was subsequently concentrated using rotary evaporator. The methanol extract of a sample was partitioned by petroleum ether ( b.p. $40-60$ ${ }^{0} \mathrm{C}$ ), Diethyl ether and ethyl acetate following a well known method [ 9] .Each step was repeated at least thrice to ensure complete extraction. The petroleum ether fraction was discarded as it contained fatty substances and chlorophyll. The diethyl ether fraction of both the samples (leaves and stem ) referred as fraction I(a) \& I (b) respectively, was in turn, used for analysis of free flavonoids and the ethyl acetate fraction of both the sample (leaves and stem) referred as fraction II(a) \& II(b) respectively for bound flavonoids. Both the diethyl ether fractions were vaccum dried resulting into fraction I (a) and I(b) in solid state. Next, both the ethyl acetate fractions were hydrolyzed with $7 \%$ sulfuric acid for two hours and filtered. The filtrate was extracted with ethyl acetate in a separating funnel. Some water was added to separate the two layers. The sugars after hydrolysis were freed from bound state and became soluble in more polar aqueous layer while flavonoids, if present, would be transferred into ethyl acetate layer. The upper ethyl acetate layer was washed repeatedly with distilled water to neutrality, dried in vaccum to obtain fraction II(a) and fraction II(b) in solid state. These were analyzed for bound flavonoids.

\subsection{Identification of Flavonoids}

The TLC was used as a qualitative technique to identify the flavonoids present in the plant material by comparing the $\mathrm{R}_{\mathrm{f}}$ values of all the four fractions I(a), I(b), II(a) \& II(b) with the $R_{f}$ values of standard flavonoids samples. The procedure involved coating glass plates with thin layer $(250 \mathrm{~m} \mu)$ of silica gel $\mathrm{G}$, drying the plates at room temperature, and activating them at $100^{\circ} \mathrm{C}$ for 30 minutes and cooling to room temperature prior to loading of samples. Four numbers of coated and activated plates were taken and a base line 1 inch above the bottom edge was drawn by pencil. Care was taken that lining did not scratch the silica coating. In all the four plates standard flavonoids namely Quercetin, Kaempferol, and Myrecetin were applied on the base line. In addition to these three spots, each plate in turn, was spotted with fractions I (a), I (b), II (a) \& II (b ) respectively. All fractions and standard were used as concentrated solutions in methanol. Thus every fraction was chromatographed with three standard compounds. The plates were developed in an air tight chromatographic chamber saturated with solvent system ( n butanol : acetic acid : water, $125: 72: 3$ ). The developed plates were air dried and visualized under UV light at $365 \mathrm{~nm}$ alone and in presence of ammonia fumes. The fluorescent spots coinciding to standard Quercetin and Kaempferol were identified on all the plates. No spot was observed corresponding to Myrecetin. The plates when exposed to ammonia fumes showed brownish spots. For each sample the $R_{f}$ values were calculated and the average value was compared with that of standard. A few plates were sprayed with $10 \% \mathrm{NaOH}$ for further confirmation which turned the spots yellow. The $\mathrm{R}_{\mathrm{f}}$ values for the standard compounds were determined as: Quercetin - 0.80, Kaempferol - 0.85 and Myrecetin -0.32 .The set of four plates was chromatographed five times and the $R_{f}$ values reported are the average values.

\subsection{Quantitative Estimation of Flavonoids}

PTLC is a useful technique for isolation and purification of small quantity of a sample. It allows for rapid separation of a number of components in a sample of natural extract. It is useful for obtaining a profile of the products. Actually, PTLC is a macro - TLC analysis in which one can not only qualitatively indentify the products but can actually separate, purify and collect the samples quantitatively.

The glass plates of dimension $20 \times 20 \mathrm{~cm}$ were thickly coated $(400-500 \mathrm{~m} \mu)$ with silica gel $\mathrm{G}$, dried at room temperature, activated at $100^{\circ} \mathrm{C}$ for 30 minutes and again cooled to room temperature for use in PTLC. Each activated silica gel plate was processed as follows: A pencil line with very light hand, without harming the gel coating, was drawn from 1 inch of a side of the plate. This was taken as origin line. A fraction (I(a), I(b), II(a). or II(b) was weighed and dissolved in about $1 \mathrm{ml}$ methyl alcohol to make a concentrated solution. This solution was carefully deposited on the origin line leaving 1 inch from either sides of the plate with the help of a short pipette. It was allowed to dry at room temperature. Another layer of the solution was similarly loaded on the previous dried layer. This way, 3-4 layers on one-another were loaded on a plate. Similarly, rest of the solution was loaded on some other plates. Care was taken that the solution was loaded uniformly throughout the band and the layer upon layer should not diffuse on the surface. These plates were chromatographed in an air tight PTLC chamber containing about $200 \mathrm{ml}$ of organic solvent system $\mathrm{n}$ Butanol: Acetic acid: Water (4:1:5), upper layer. The developed glass plates were dried at room temperature and visualized in UV light at $365 \mathrm{~nm}$. Two fluorescent bands were seen on the plate. The position of the bands was ascertained by exposing the plate to ammonia, when two brown bands were observed. The $\mathrm{R}_{\mathrm{f}}$ values of these bands were calculated and compared with those of standard compounds observed in section 2.4. The comparison showed that the sample 
contained Quercetin and Kaempferol. The bands were scrapped cautiously and collected separately along with the adsorbent. The adsorbent was removed by eluting the mixture with ethylacetate. The elutes were vaccum dried over anhydrous sodium sulphate. The dried substances were recrystallised and weighed. This weight was used to calculate total free and bound flavonoid content per gram of a fraction. The entire process was repeated for each and every fraction. It was found that each fraction contained the same two flavonoids namely, Quercetin and Kaempferol. The quantitative amounts of flavonoids in each fraction are reported in table 2. Apart from $R_{f}$ values the presence of quercetin and kaempferol were confirmed by melting point determination and UV \& IR spectroscopy. Furthur, the quantitative assay of the flavonoids were done by spectrophotometric method.

\subsection{Total Flavonoid Content (TFC) by Spectrophotometer}

The aluminium chloride assay method [10] was used with little modification to determine TFC in each of the four extracted fractions and the compounds separated from these fractions. Different solutions of standard Quercetin in the concentration range $10-100 \mu \mathrm{g} / \mathrm{ml}$ were prepared.

Beer's law was found valid upto $400 \mu \mathrm{g} / \mathrm{ml}$. $1.0 \mathrm{ml}$ of a Quercetin solution was mixed with $0.3 \mathrm{ml}$ of $5 \% \mathrm{NaNO}_{2}$. After 5 minutes, $0.3 \mathrm{ml}$ of $10 \% \mathrm{AlCl}_{3}$ was added .Then after 6 minutes, $2.0 \mathrm{ml}$ of $1 \mathrm{M} \mathrm{NaOH}$ was added and the total volume of the solution was made up to $10 \mathrm{ml}$ with distilled water. The solution was well shaken and kept for 10 minutes for incubation at room temperature.

A portion of this solution was taken to measure the absorbance against a freshly prepared reagent blank in which $\mathrm{AlCl}_{3}$ was replaced by distilled water. Each solution was given the same treatment for measuring the absorbance. Before recording absorbance of a solution, the solution having concentration $100 \mu \mathrm{g} / \mathrm{ml}$ was taken and its absorbance at different wave lengths in the range 300 to $600 \mathrm{~nm}$ was scanned. The maximum absorbance, $\chi \max$, was noted at 510 $\mathrm{nm}$. Therefore, all the absorbance readings were taken at $510 \mathrm{~nm}$. The absorbance values when plotted against corresponding concentrations produced a straight line $\mathrm{Y}=$ $0.0052 \mathrm{X}+0.1573$. This was used as calibration curve for computing concentration of the test solutions. Based on the measured absorbance, the concentration of flavonoids was $\mathrm{read}$ in $\mu \mathrm{g} / \mathrm{ml}$ on the calibration line; then the flavonoid content was calculated in terms of $\mathrm{mg} / \mathrm{g}$ dry weight as per the standard method [10]. The results are compiled in Table 2.

\subsection{Anti- Oxidant Activity}

1,1 diphenyl 2- picryl hydrazyl ( DPPH ) method [ 11,12 ] for determining anti-oxidant ability of a plant material is a rapid, simple and inexpensive method. The method can be used for solid or liquid samples and is not specific to any particular anti-oxidant component. It applies to the overall capacity of a sample. The method is based on measuring the anti-oxidant ability of a sample in terms of hydrogen donating or radical scavenging ability.In a typical experiment $39.4 \mathrm{mg}$ of DPPH was dissolved in 1 litre of methanol to give a solution strength of $0.1 \mathrm{mM}$. Now, $1 \mathrm{ml}$ of this solution was reacted with $3 \mathrm{ml}$ of methanolic solutions of different concentrations of fraction II (a). Only one fraction namely fraction II (a) was sufficient for examining the anti-oxidant activity as all other fractions contain the same flavonoids in lesser amounts. Since the reaction has kinetics, the solutions were allowed for 30 minutes to interact and attain the reaction equilibrium. Then, the absorbance of these solutions was measured on spectrophotometer at $517 \mathrm{~nm}$. Absorbance of a blank (control) solution, prepared by mixing $1 \mathrm{ml}$ of DPPH with $3 \mathrm{ml}$ of methanol was always noted along with that of test solutions. The anti-oxidant capacity of the sample was calculated in terms of \% scavenging activity as follows:

$$
\% \text { Scavenging Activity }=\left(1-\mathrm{A}_{1} / \mathrm{A}_{0}\right) \times 100
$$

where $A_{0}$ is the absorbance of the control and $A_{1}$ is absorbance of a solution in which DPPH and a sample concentration have reacted for 30 minutes..Since pale yellow color of a test solution due to picryl group always remains in the solution, and the reaction between DPPH and the plant fraction may take considerable time for $100 \%$ reaction to complete, it was thought safer to consider the absorbance reduced to $100 \%$ exactly at the point when purple colour disappears and pale yellow remains.

In order to compare the anti-oxidant activity of our green product with that of the known compound, we compared the results with those obtained with vitamin $\mathrm{C}$. For this, the above process was repeated with vitamin $\mathrm{C}$ solutions replacing fraction II (a) solutions. The results are shown in Figure 1.

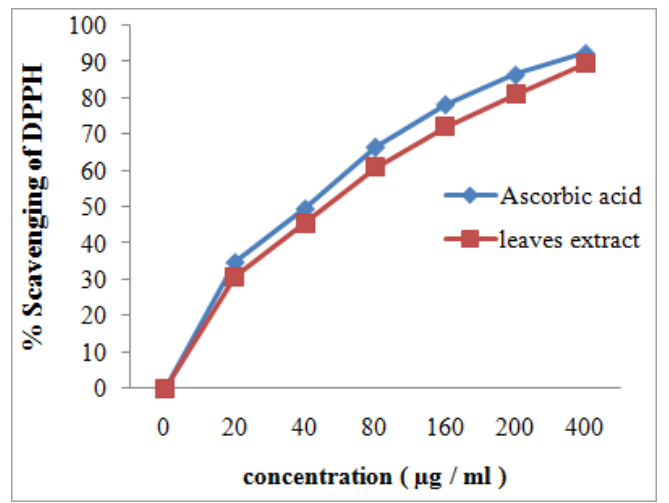

Figure 1. Comparison of Anti-oxidant activity of Ascorbic acid and Urena lobata leaves (methanolic extract).

\section{Results and Discussion}

The DPPH is characterized as a stable free radical by virtue of the delocalization of the spare electron over the whole molecule, so that the molecules do not dimerize, as would be the case with most other free radicals. The delocalization gives rise to the deep violet color characterized by an absorbance band in methanolic solution at $517 \mathrm{~nm}$. When DPPH is mixed with a substance (Anti-oxidant) that 
can donate a $\mathrm{H}$ atom, its free electron forms a bond with $\mathrm{H}$ atom resulting into loss of violet color. Nevertheless, the residual pale yellow color still remains due to presence of the picryl group. If $\mathrm{Z} \cdot$ represents $\mathrm{DPPH}$ free radical and $\mathrm{AH}$ the $\mathrm{H}$ donor molecule of the anti-oxidant sample, then

$$
\mathrm{Z}^{\bullet}+\mathrm{AH} \rightarrow \mathrm{ZH}+\mathrm{A}^{*}
$$

Where $\mathrm{ZH}$ is the reduced form of $\mathrm{DPPH}$ and $\mathrm{A}^{\circ}$ is the free radical produced in this step. This free radical will undergo further reactions which control the overall stoichiometry, that is, the number of DPPH molecules reduced by one molecule of the anti-oxidant. Free radical $\mathrm{A}^{*}$ further reacts with another molecule of the same kind,

$$
\mathrm{A}^{\cdot}+\mathrm{A}^{\cdot} \rightarrow \mathrm{A}-\mathrm{A}
$$

This leads to the reduction of two DPPH molecules by two anti-oxidant molecules, that is a 1:1 stoichiometry . However, the molecules like vitamin $\mathrm{C}$ ( Ascorbic acid) have two adjacent $\mathrm{H}$ atoms, therefore one molecule of vitamin $\mathrm{C}$ has the capacity to reduce two molecules of DPPH free radical. The mechanism may be understood by following scheme which leads to a 2:1 stoichiometry.

Step 1.

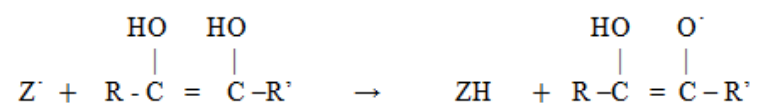

Step 2.

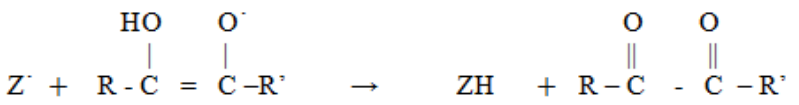

Figure 1. shows a record of the values of \% scavenging activity obtained as described in section 2.6 for fraction II (a) and vitamin $\mathrm{C}$. A comparison of the plots clearly indicates that the anti-oxidant activity of our plant material over a wide range of concentration is comparable with that of vitamin $\mathrm{C}$. It establishes that the Urena lobata extract provides a green anti-oxidant which can be used as a food supplement in place of synthetic anti-oxidant like vitamin $\mathrm{C}$. It is a well known fact that the anti-oxidant activity of a plant material depends on the richness of flavonoid contents in it. So, it will be in line to examine the free, bound and total flavonoid content per gram of the plant extract. The results of TLC analysis described in section 2.4 have been summarized in Table1. An observation of the experimental $\mathrm{R}_{\mathrm{f}}$ values, melting points, UV absorption maxima ascertained that the compounds separated from the plant extracts (leave and stem) are Quercetin and kaempferol. Furthur the presence of these compounds was confirmed by observing that the IR spectral peaks of the isolated compounds superimposed on tha $t$ of standard reference compounds.

\begin{tabular}{|c|c|c|c|c|c|c|c|c|c|c|}
\hline \multirow{2}{*}{$\begin{array}{l}\text { Fractions Isolated } \\
\text { From Diethylether }\end{array}$} & \multicolumn{3}{|c|}{$\begin{array}{l}\text { Free Flavonoids } \\
\text { (mg/g.fraction wt) }\end{array}$} & \multirow{2}{*}{$\begin{array}{l}\text { Fractions Isolated } \\
\text { From Ethyl acetate }\end{array}$} & \multicolumn{3}{|c|}{$\begin{array}{l}\text { Bound Flavonoids } \\
\text { (mg/g.fraction wt) }\end{array}$} & \multicolumn{3}{|c|}{$\begin{array}{l}\text { Total Flavonoids } \\
\text { (mg/g.fraction wt) }\end{array}$} \\
\hline & $\mathbf{Q}$ & $\mathbf{K}$ & $\mathbf{T}$ & & $\mathbf{Q}$ & $\mathbf{K}$ & $\mathbf{T}$ & $\mathbf{Q}$ & $\mathbf{K}$ & $\mathbf{T}$ \\
\hline Fraction I(a)( leaves) & 0.22 & 0.33 & 0.55 & Fraction II(a)( leaves) & 0.30 & 0.35 & 0.65 & 0.52 & 0.68 & 1.20 \\
\hline Fraction $\mathrm{I}(\mathrm{b})($ stem $)$ & 0.15 & 0.20 & 0.35 & Fraction II (b) (stem) & 0.18 & 0.27 & 0.45 & 0.36 & 0.47 & 0.80 \\
\hline
\end{tabular}

Table 1. Qualitative identification of the isolated green compounds.

\begin{tabular}{lll|ll}
\hline $\begin{array}{l}\text { Color of the } \\
\text { compound }\end{array}$ & $\begin{array}{l}\text { Color of TLC spots in } \\
\text { presence of ammonia }\end{array}$ & $\mathbf{R}_{\mathbf{f}}$ values & $\boldsymbol{\chi}_{\text {max }}(\mathbf{n m})(\mathbf{M e O H})$ & Melting Point \\
\hline Yellow & Brown & 0.75 & $252,267,306,370$ & $\begin{array}{l}\text { Name of the isolated } \\
\text { compound }\end{array}$ \\
Yellow & Brownish-yellow & 0.82 & $253,268,324,367$ & $315^{\circ} \mathrm{C}$ \\
\hline
\end{tabular}

Table 2. Quantitative Estimation of Total Flavonoids (Free \& Bound) in isolated fractions of Urena lobata leaves \& stem.

Abbreviations : Q- Quercetin ; K - Kaempferol ; T - Total

The results of PTLC analysis described in section 2.5 and further confirmed by spectrometric analysis have been compiled in Table 2. A perusal of Table 2. indicates that both Quercetin and Kaempferol in Free and Bound states are contained in greater percentage in leaves of Urena lobata as compared to its stem. Summarily, our studies reveal that Urena lobata is a good green source of flavonoids which are useful for human health.

\section{References}

[1] V. Lovo, A. Patil, A. Pathak, N. Chandra, Free radicals, Antioxidants and Functional Foods : Impact on Human Health, Pharmacognosy Reviews, 4(8),(2010), 118-126.

[2] A.B., Shinde, N.B Shrigadi, S.D. Samant, Tert-Butylation of
Phenols using Tert-Butyl Alcohol in the Presence of $\mathrm{FeCl}_{3}$ modified Montmorillonite K10 Appl. Catal. A: Gen., 276, (2004), 5-8.

[3] N. Bhatt, P. Sharma, A. Patel, A. Selvam , Supported 12 Tungstophosphoricacid : An Efficient And Selective Solid Acid -Catalyst for Tert- Butylation of Phenol and Cresols, Catal. Comm., 9(7), (2008), 1545 -1550.

[4] H.U. Shen, Z.M.A. Judeh, C.B. Ching, Q.H. Xia, Comparative Studies on Alkylation of phenol With Tert- Butyl Alcohol in Presence of Liquid or Solid Acid Catalysts in Ionic Liquids, J.Mol. Catal. A, .212 (1-2), (2004), 301 -308.

[5] A. R. Proteggente, A.S. Pannala, L. Van Buren, E.Wagner, S. Wiseman, F.Vande Put, C.Dacombe, C.A. Rice- Evans, The Antioxidant Activity of Regularly Consumed Fruit and Vegetables Reflects their Phenolic and Vitamin C Composition, Free Radical Research, 36 (2), (2002), 217-233. 
[6] J.K. Francis, Atlas of Florida Vascular Plants , Institute of Systematic Botany, University of South Florida, Tampa, FL., 2003.

[7] R. Freedman, Famine Foods: Malvceae, Perdue University, Perdue , IN , 1998.

[8] Food and Agriculture Organization of the United Nations, Rome, in its report Food Composition Table for Use in Africa, 2003.

[9] S.S.Subramanian, S. Nagarajan , Flavonoids of the seeds of Crotlaria retusa and C. striata, Curr. Sci., 38 , (1969), 65 - 68.
[10] T.J.Mabry, K.R. Markham, M.B. Thomas, The systematic identification of flavonoids, Springer- Verlag, Berlin, 1970.

[11] V. Bondet, W. Brand-Williams, C. Berset, Kinetics and Mechanisms of Anti-oxidant activity using the DPPH Free Radical Method, Food Science and Technology, 30, (1997), 609-615.

[12] W. Brand -Williums , M.E. Cuvelier, C. Berset, Use of a Free radical Method to evaluate Anti-oxidant Activity, Food Science And Technology, 28, (1995), 25-30. 